these two forms of copper and found that there is certainly not more than 25 per cent copper in the form of the mirror. It may have been considerably less, in accordance with the above calculation.

The nature of the 'volatile copper compound', or more correctly 'compounds', is therefore definitely established, and the main lines of thermal decomposition of cupri-, cuprous and silver formate are determined with reasonable certainty.

A detailed account of the work will appear in Magyar Technika.

${ }^{1}$ Körösy, F., Nature, 160, 21 (1947).

2 Maltby, J. G., Nature, 160, 468 (1947).

Angel, A., and Harcourt, A. V., J. Chem. Soc., 81, 1385 (1902).

- Kohlschütter, V., Helv. Chim. Acta, 18, 980 (1930); 17, 1097 (1934).

s Angel, A., J. Chem. Soc., 89, 345 (1905).

\section{ENGINEERING STUDENTS AND MATHEMATICS}

$\mathrm{O}^{\mathrm{N}}$ the morning of September 14, at a joint session of Sections A (Mathematics) and G (Engineering) of the British Association, a discussion took place upon the subject of "Applicable Mathematics".

Wing-Commander T. R. Cave-Browne-Cave (president of Section $\mathrm{G}$ ) in his opening remarks emphasized that mathematics is a matter of importance, but often of difficulty, to engineering students.

Mr. D. N. de G. Allen (Mathematics, Imperial College of Science and Technology, London) said he spoke as one engaged in teaching mathematics mainly to undergraduate and postgraduate engineering students. $\mathrm{He}$ would consider not the oft-asked question: "What does the engineer require of mathematics?", but rather "What does his mathematics require of the would-be engineer ?" Mathematics is an integral part of engineering science, evolved to satisfy the demands of engineering, and should be used by the engineer as one of the tools of his trade. The obstacles the engineer has to overcome are : first, the fact that his problem is stated in engineering terms, and must at the outset be translated into mathematical terms; secondly, the mathematical problem must be set up; thirdly, a mathematical solution must be found ; fourthly, this solution must be translated back into an engineering solution. In stage one it is desirable that all the available data be explicitly stated. In stage two it is especially important to realize whether the mathematical problem is, or is not, complete in itself. In stage three the maximum possible use should be made of simple ideas, simple methods, and simple functions. In particular, numerical methods, which enable formerly intractable problems to be solved by simple arithmetic, using processes which are intelligible at every step, have great merit, at postgraduate as well as at undergraduate level. At the same time, however, the more advanced mathematical methods should not be entirely overlooked; the engineer should be aware of the existence of such methods, and should know when, and how, to consult the mathematical expert.

Dr. J. A. Pope (Engineering, University of Sheffield) pointed out that engineering, a branch of applied science the object of which is to create objects of immediate utility, calls upon many branches of science; and while the engineer could not be expected to have a detailed knowledge of all these branches, he must know enough to be able to appreciate the significance of the information supplied by the specialist. But engineering is also a delicate balance between tradition and the application of scientific knowledge, the 'factor of safety' representing the traditional element in design. Turning to mathematics, he suggested that any mathematical process which the engineer is prepared to adopt must be susceptible of a physical interpretation, and this, indeed, at every stage. Another necessity for the engineer is 'pictorial vision', and this can be both aided and exploited by copious use of graphical methods in teaching mathematics; abstract ideas can with advantage be handled by means of graphical representation, for exæmple, vector diagrams, and the Argard diagram for complex quantities involving $i=\sqrt{ }(-1)$. After brief reference to some essential elements, such as power and Fourier series, integration, partial differentiation, and differential equations, the advantages of numerical methods (step-by-step and 'relaxation') were mentioned, and the necessity of some more advanced mathematics for the abler men was pointed out. But there is a difference in intellectual make-up between the mathematician, master of abstract thought, and the engineer, servant of practical necessity. This has sometimes led to barbarous treatment of mathematical lecturers by otherwise well-behaved engineering students, and to a 'pearls before swine' attitude on the part of some of the former.

Mr. F. S. Snow (president, Institution of Structural Engineers)-whose contribution was read for him on account of illness-referred more particularly to the extent to which the average engineer needs to utilize mathematics in the solution of day-to-day problems. The more experienced an engineer, the less mathematics he personally uses in his day-to-day business. He is, however, able to use the mathematics he learned as a student when necessary, and knows where to turn for the more advanced methods. But the experienced engineer will not profess to be able to design, say, a reinforced concrete column by eye alone, and he will employ younger engineers, and perhaps even mathematicians, to perform the caleulations inseparably connected with design. For these, familiarity with mathematics, at least as far as the calculus, is essential. From time to time, new theories based on new assumptions are produced, usually by the mathematicians, and at first the engineer must rely upon the resulting formula; reinforced concrete shell roofs are an example. On the other hand, the practical engineer is faced with uncertainty as to data, as to the properties of many of the materials he uses, and as to the excellence (or otherwise) of the workmanship. Mathematically elegant designs may be scrapped because they demand a higher standard of workmanship than is generally available. Thus, while all engineers should attain a standard in mathematics at least as high as that prescribed by the professional institutions, they require also to amass a vast amount of experience.

Dr. A. G. MacFarlane (Telecommunications Research Establishment, Malvern) devoted himself to a particular, rather than a general, aspect of the subject under discussion, namely, the calculus of variations and its usefulness as a method for the solution of physical and engineering problems. He referred to the development of the principle at the end of the eighteenth and beginning of the nineteenth 
centuries as outstanding, the most important feature being Hamilton's demonstration that the equations of dynamies might be derived from a stationary principle. As a result, variational principles now occupy a central position in theoretical.physics, but are still not used as much as they might be. Most problems must be idealized before they become tractable, but the more powerful the mathematical technique, the less the amount of idealization necessary; it is therefore desirable to review all the possible methods when tackling any problem. Most physical problems are usually stated mathematically in terms of differential equations and boundary conditions. But differential equations are 'local', and use of integrals is advantageous, because they include the behaviour of the functions over the whole range of variables, and also because they incorporate the boundary conditions. Such methods are (1) integral equations, (2) variational principles. Using for illustration the diffraction of electromagnetic waves by a slit, the advantages of the variational methods were outlined. The variational equations may be solved, for example, by Ritz's method or by 'relaxation'. Another advantage is that the integral which is to be made stationary usually represents a quantity of great physical significance.

Prof. W. G. Bickley (Mathematics, Imperial College of Science and Technology, London) said that the opening speakers had considered the mathematical education of the ordinary engineer, and the mathematical needs of the extraordinary engineer, in what seemed to him about the right proportion, and had underlined the fact that the problem exists at two levels. At the lower level the problem is not so much what to teach, as how (and to some extent when) to teach it. Following up Mr. Allen's emphasis upon the necessity of translating from the language of engineering to the language of mathematics, he stressed the desirability of the lecturer in mathematics being able to speak the engineer's language. One of the greatest obstacles in the way of the enlightened mathematician is the still too prevalent attitude that mathematics should be avoided like a plague, instead of used to increase efficiency. It is inconsistent to advocate modern machine tools in the workshop, and fall back upon the equivalent of cold chisel and file for thinking. So absurd, indeed, that he wondered whether the mathematicians had always given the engineering students a fair deal, whether the barbarity referred to by Dr. Pope was partly their fault-if there was a 'pearls before swine' attitude, then barbarity was just retribution. Speaking of engineering students as amenable to sympathetic treatment, and of teaching them mathematics as a rewarding and enjoyable task, he urged his mathematical colleagues to take this task seriously. Familiarity with the mathematical chapters of the engineering text-books would give much food for thought, in more ways than one. Improvements were, of course, being made, and he instanced the work of a sub-committee set up by the Mathematical Association. But education is a slow process. Perhaps some of his students, becoming lecturers in engineering, might condition the minds of their students to more and better mathematics.

Turning to the high-level problem, Prof. Bickley said two things are necessary-to be able to give a 'top-dressing' of applicability to the graduate mathematician, and a top-dressing of mathematics to the abler graduate engineer. For this a central "Institute for Applicable Mathematics" is desirable.
Attached to a university, but maintaining close contact with research institutions, with a staff collectively conversant with classical and modern mathematics, mathematical physics and technology, interested in seeing where and how mathematics has aided and can aid the scientific worker and technologist, such an institute would so equip its students that they might fit very quickly into any research institution or could become teachers in the technical colleges and universities. Part-time and refresher courses, for those already engaged in research or teaching, would also be provided. Indeed, the principle had been agreed, but lack of funds has prevented a start being made. Could industry, perhaps on a cooperative basis, come to the rescue ? If so, the outlay would earn rich, if perhaps indirect, dividends.

Sir Richard Southwell remarked upon the friendliness of the discussion. He thought this a good thing, because in his opinion there is a fundamental difference of outlook between mathematician and engineer, in consequence of which they would have to agree to differ-and agreement to differ is possible only between friends. He gave some illustrations of the difference of outlook. As regards calculus of variations, he thought that many engineers were already familiar with examples of the idea, for example, minimum strain energy as a basis for analysis of structures. Many abstract ideas could be assimilated if they were approached through concrete examples, and he agreed with Dr. Pope's emphasis upon keeping the physical meanings in view. $\mathrm{He}$ also instanced Rayleigh's use of variational methods for deducing governing equations throughout his great "Theory of Sound".

Mr. R. A. Fairthorne agreed upon the necessity of properly stating the problem. To do this needs a realization of what is essential, and he had found lawyers and journalists, who habitually have to endeavour to see the essence of a problem they do not understand, better at this than mathematicians or engineers. Training in logic or philosophy greatly assists. Prof. H. S. Ruse commented upon the general keenness of engineering students. He suggested that what was perhaps more important to the engineering student than acquisition of technique was an appreciation of mathematical methods of thinking. Prof. S. J. Davies said that what he would wish for his students was that the mathematicians would teach them mathematics. He mentioned that a water turbine recently constructed according to the 200-year-old design of the mathematician Euler had an efficiency of more than 60 per cent.

Prof. Bickley thought that Sir Richard Southwell tended to exaggerate the difference between mathematicians and engineers; but that so far as it did exist, a friendly agreement to differ, along with a sincere attempt to understand one another's language, were desirable. He agreed with Mr. Fairthorne upon the importance of being able to discern the crux of any problem, and thought that the conciseness and precision of mathematical expression were a great help in this direction. He was glad that Prof. Ruse could agree about the keenness of engineering students. He could agree with Prof. Davies, and asserted that the one thing that the mathematics course should not appear to be was a sequence of $a d$ hoc tricks for doing particular jobs. He did, however, think that the best chance of getting engineering students to appreciate mathematics for its own sake was to start with a recognition and an understanding of their interests and habits of thought. 